\title{
Infiltrados. Crónica de la corrupción en la PNC
}

Infiltrados es una obra original, basada en artículos periodísticos propios del autor, producidos durante su carrera, y en otros artículos publicados por sus colegas. También toma como referencia documentos oficiales escritos por autoridades de las instituciones del gobierno salvadoreño en el periodo de estudio; retoma, además, comunicaciones de autoridades del gobierno estadounidense. Complementa esta información con testimonios de personas que fueron víctimas, victimarios o testigos del proceso de infiltración del crimen organizado en la Policía Nacional Civil (PNC). El autor es periodista-investigador desde 1993, y entre 2009 y 2011 fue funcionario del primer gobierno de izquierda en El Salvador.

Esta obra pretende exponer la realidad que se vive en la PNC de El Salvador con relación a la infiltración del crimen organizado, desde su creación, justo después de haberse firmado la paz en el país en 1992. Brinda a la comunidad académica y autoridades interesadas, y obligadas con el desarrollo real de las instituciones de justicia, una cronología de hechos que hace suponer las vulnerabilidades que la institución policial ha mantenido durante su desarrollo y la vuelven susceptible a la penetración del crimen organizado.

El libro se desarrolla en diez capítulos, en los que se explica la génesis de la Policía y la forma en que el crimen organizado la infiltró. Ofrece una explicación de la manera en que se conformó la institución policial y la relación que existiera entre los funcionarios nombrados y los personajes del crimen organizado. Además, hace una relación de funcionarios de gobierno que han tenido participación directa o indirecta con los hechos que se presentan, no dejando de mencionar a salvadoreños involucrados con el crimen organizado que han tenido vínculos con los funcionarios policiales y demás autoridades, incluyendo operadores de partidos políticos.

La del libro es una edición de buena calidad y su lectura se muestra cómoda y entretenida. La tesis que el autor defiende es que la institución policial nació infiltrada por estructuras del crimen organizado que existían antes del fin de la guerra civil de la década de los ochenta en El Salvador. 


\section{LIBROS}

En la obra se puede encontrar información y argumentación acerca de la penetración del crimen organizado en la PNC. Esta tesis aún no ha perdido vigencia, por dos razones: una, la mayoría de las personas que involucra el autor en su investigación aún pertenecen a las estructuras de la PNC y ocupan cargos importantes en la institución; y dos, la institución, como sistema, no ha sufrido cambios sustanciales a raíz de las depuraciones realizadas desde su origen.

Esta publicación fue recibida con mucha expectativa en la sociedad salvadoreña interesada en atender la problemática; presenta información cronológicamente ordenada, sistematizada y bien relacionada, juntando datos dispersos, publicados en medios de comunicación e instituciones oficiales de gobierno. Ha provocado numerosos comentarios en los medios de comunicación por el tipo de información que se expone.

Brinda un aporte importante a la comunidad salvadoreña porque presenta evidencia documental que respalda los testimonios de testigos claves en los hechos que se relatan; además de hacer una buena relación de las inconsistencias que se presentaron en la PNC desde su creación y los elementos que afectaron, desde entonces, el buen desarrollo institucional y el cumplimiento de su objetivo fundamental de colaborar en la seguridad de la población. Concluye el autor que el "pecado original" de la PNC fue el ingreso irregular de exmiembros de la comisión de investigación de hechos delictivos y de la Unidad Ejecutiva Antinarcóticos; argumento que debería de ser tratado con más profundidad para identificar, si los hubiera, otros elementos que han incidido para que la institución no gozara de una coraza protectora para la penetración del crimen organizado.

Sin embargo, se identifica una debilidad en la obra, a pesar de que el autor hizo los intentos para superarla, y es la falta de testimonios de los personajes señalados de tener vínculos con el crimen organizado, especialmente los funcionarios policiales. El reto queda en el terreno de las instituciones, a las que les corresponde verificar, confirmar y reflexionar acerca de las acciones que se deben adoptar, a raíz de la información expuesta; y en el de los señalados, quienes tienen la oportunidad de desvirtuar o demandar al autor de la obra, en caso de sentirse ofendidos por las acusaciones, si cuentan con los elementos de prueba para desvirtuarlas.

Además, considero que esta obra deja la sensación de que todos los miembros de la PNC deberían de ser depurados, dejando de lado que existe un alto porcentaje de personal policial que ha permanecido en la 


\section{LIBROS}

institución, desde sus inicios, tratando de contrarrestar la penetración del crimen y haciendo un buen trabajo como servidores públicos, con sacrificio, honestidad, compromiso, profesionalismo y ética, entre otros.

En la obra existen elementos valiosos que deben de retomar las autoridades de seguridad pública para examinar el sistema de justicia en general, siendo este un compromiso que debe asumir el Estado.

El autor ha sido cuidadoso en la publicación de la información expuesta a raíz de que detalla, en las primeras páginas del libro, los filtros que se utilizaron para que la información fuese publicada. Mucha se le quedó en el tintero, dice, por no haber logrado superar los requisitos establecidos.

Esta obra se vuelve de lectura obligatoria para la comunidad salvadoreña, en general, y en especial para los involucrados en el tema de seguridad pública.

Sinopsis elaborada por William Riquelmi Padilla Mirón Jefe de la Unidad de Planificación Institucional, ANSP 